\title{
Effects of Neuromuscular Training on Muscle Activity and Balance Ability in Badminton Club Members with Chronic Ankle Instability
}

\author{
Sam-Heon Park \\ Department of Physical Therapy, Graduate School, Sehan University, Yeongam-gun, Jeollanam-do, Korea
}

\begin{abstract}
Purpose: This study was conducted to identify the effects of neuromuscular training performed on badminton club members' to improve muscle activity of the lower extremities and static and dynamic balance tests.

Methods: The subjects were 20 badminton club members with chronic ankle instability who were randomly divided into a neuromuscular training group and a balance training group, each with 10 patients. Both exercises ware performed three days per week for 30 minutes a day over six weeks.

Results: The neuromuscular training group showed increased muscle activity of the lower extremities compared to the balance training group. Neuromuscular training increased balance ability better than the balance training group, showing a significant difference and better efficiency of neuromuscular training when compared to balance training.

Conclusion: This research evaluated neuromuscular training as an intervention for badminton club members with chronic ankle instability and compared the differences in muscle activity of the lower extremities and balance ability; as a result of the effective frequency for improving performance, there was a significant difference in muscle activity of lower extremities and balance ability of the neuromuscular training group and the control group.
\end{abstract}

Keywords: Neuromuscular training, Muscle activity, Balance, Badminton, Chronic ankle instability.

\section{서 론}

오늘날 과학기술의 발달에 따른 산업화 및 경제성장, 주 5 일 근무제 등으로 인해 여가시간이 증가하면서 여가에 대한 관심이 급속히 증 가하고 있다. 특히 산업화의 진전에 따른 노동구조의 변화로 인하여 인간의 육체적 활동이 감소되고, 여가시간이 증가하게 됨에 따라 운 동이나 스포츠에 대한 인간의 활동욕구를 증대시켜 생활체육이 현 대인의 삶과 밀접한 관계 맺기 이르렀다. 현대사회에서 일과 여가는 인간생활을 구성하고 인간의 삶의 질 향상에 필수요소가 되었다. 삶 의 질적인 향상을 추구하기 위하여 여가 시간의 상당 부분을 스포츠 활동에 할애함으로써 스포츠의 대중화 및 보편화 현상이 가속화되 고 있다. ${ }^{1}$ 이처럼 스포츠는 여가생활의 중요한 한 부분으로 자리를 잡았으며, 특히 배드민턴은 남녀노소 누구나 참가할 수 있는 실내 스 포츠로 날씨에 관계 없이 언제나 참가할 수 있다는 장점과 경기방식

Received Jul 11, 2016 Revised Aug 13, 2016

Accepted Aug 22, 2016

Corresponding author Sam-Heon Park

E-mail ehwns2@naver.com
또한 단식과 복식, 혼합복식 등 다양한 방법으로 진행할 수 있어 여 러 재미요소를 두루 즐길 수 있는 스포츠라 할 수 있다. ${ }^{2}$ 배드민턴은 순발력, 지구력, 민첩성, 유연성 등의 여러 가지 체력인자를 사용하는 운동이며 관절의 가동 범위 또한 큰 운동이다. 모든 종목의 스포츠 는 종목마다 특색 있는 기술이 있으며, 이 기술을 습득하려면 장기간 의 훈련이 필요하게 되고 훈련 시 기술이 부족하면 상해를 입을 가능 성이 있다. ${ }^{3}$

배드민턴 동호인을 대상으로 운동상해 유병 분석에서 하체부위 상해 발생이 발목 $86.1 \%$ 로 가장 높았으며, 관절의 가장 많은 상해발생 종류로 염좌 $42.6 \%$ 로 가장 높게 나타났다. 발목 염좌는 발목관절의 갑작스런 발바닥 굽힘 상태에서 안쪽 돌림을 일으켜 외측인대가 손 상되는 급성 손상과 과훈련, 과사용 또는 염좌 후 완전한 재활 처치 등의 부재로 인해 나타나는 만성적인 손상으로 나눌 수 있다. ${ }^{5}$ 발목 염좌는 발목 관절의 인대 조직뿐만 아니라 발목관절 주위 신경 조직
Copylight (C2016 The Korea Society of Physical Therapy

This is an Open Access article distribute under the terms of the Creative Commons Attribution Non-commercial License (Http:// creativecommons.org/license/by-nc/4.0.) which permits unrestricted non-commercial use, distribution, and reproduction in any medium, provided the original work is properly cited. 
에 손상을 받게 되는데, ${ }^{6}$ 발목 주변에 있는 기계적수용기(mechanoreceptor)를 포함한 신경조직들이 손상을 입게 되면 균형 감각이나 관 절 위치 감각(joint position sense)의 결손을 가져오게 된다.?

만성 발목 불안정성(chronic ankle instability, CAI)이란 발목 염좌이 후 발목 인대 재손상으로 인해 병리적 느슨함에 의한 기계적 불안정 성(mechanical ankle instability)과 인대 손상 후 고유수용성감각과 신 경근 손실에 의한 반복적인 발목 불안정성과 관절 감각 불안정성을 발생시키는 기능적 발목 불안정성(functional ankle instability) 두 가지 로 분류 된다. ${ }^{8}$ 기능적 발목 불안정성은 관절의 정적 및 동적 지지능 력의 상실과 발이 꺾이는 경향으로, ${ }^{9}$ 발목 염좌에 의한 고유수용성 감각의 손상이 중추 운동 프로그램 본래의 기능을 유지하기 위해 필 요한 피드백을 손상시킴으로써 발생한다. ${ }^{10}$ 기능적 발목 불안정성은 구조적인 불안정성과 관계없이 발목관절 주위를 둘러싸고 있는 인 대, 근육, 건의 운동감각 신경의 결여, 근력약화, 협응력 저하 그리고 자세 조절능력의 부재 등의 원인에 의해 발생하는 발목관절의 반복 적인 손상이나 불안함(give-way)을 주관적 관점으로 알 수 있다. 또한 기능적 발목 불안정성을 가진 운동선수들은 착지순간 시점에서 잘 못된 위치정보로 인해 발목관절 염좌가 재발하기 쉽고 착지과정 동 안 발목관절의 움직임을 제한하려는 경향이 있다.

균형은 정적 균형과 동적 균형으로 구분되는데 정적 균형은 무게 중심점의 이동을 최소화하여 신체의 움직임 또는 흔들림을 감소시 키는 능력이고, 동적 균형은 기저면 내에서 체중을 이동 시킬 수 있는 능력을 말한다. ${ }^{11,12}$ 균형능력은 축구, 농구 그리고 체조와 같은 스포 츠의 더 나은 수행을 위한 필수적인 요소로 특히, 배드민턴에서 셔틀 콕의 속도와 방향의 갑작스러운 변화로 신체의 뒤틀림, 회전, 도약동 작처럼 기술적 움직임을 수행하게 되는 한발서기 자세가 필요하며 정확한 수행을 위해서는 디딤 다리의 안정성이 매우 중요하다. ${ }^{13}$ 그러 나 발목 불안정성 환자들은 자세조절의 손상과 함께 고유수용성 감 각과 신경근 조절 손상이 결합되어 발목관절의 평형능력, 관절의 자 세감각 저하로 인해 발목관절 주변 근육의 반응시간 지연, 안정성의 장애를 일으킨다고 하였다. ${ }^{14}$

최근 발목 불안정성 환자들을 대상으로 중심부 안정화 훈련, 키네 지오 테이핑, 고유수용성 감각훈련, 가상현실 훈련 및 신경근 훈련이 소개되고 있다. 신경근 훈련이란 고유수용성 훈련이 포함된 다양한 훈련들로 구성되어 균형 운동, 동적 관절 안정성 운동, 플라이오 메트 릭, 민첩성 훈련, 스포츠의 특정 운동들이 포함된 프로그램으로, 관 절 위치 감각을 향상시키고, 관절 안정성의 높이고 관절 보호반사를 증진시켜 하지의 부상 방지를 위한 복합적인 신체 강화 훈련 프로그 램을 말한다. ${ }^{15}$ Riemann 등 16 은 신경근 훈련이 스포츠 부상 이후 기능 적 수행 능력의 향상과 스포츠 부상과 관련된 위험성을 감소시키는 효과적인 중재라고 하였다.
$\mathrm{Lee}^{10}$ 는 기능적 발목 불안정성을 가진 축구선수들에게 신경근 훈련 을 실시한 그룹에서 균형능력의 유의한 차이를 보였으며, Santos 등17 은 만성 발목 불안정성을 가진 운동선수들에게 동요훈련을 실시한 그룹에서 하지 근활성도의 유의한 차이를 보였다. Jackson 등 ${ }^{18}$ 은 발 목 불안정성을 가진 환자를 대상으로 키네지오 테이핑을 적용한 그 룹에서 균형능력에서 유의한 차이가 있었고, Linens 등 ${ }^{19}$ 은 만성 발목 불안정성을 가진 환자를 대상을 와블 보드(wobble board)를 적용한 그룹에서 정적, 동적 균형능력에서 유의한 차이를 보였다.

본 연구는 배드민턴 동호인들을 대상으로 참여동기와 참여 정도 에 따른 운동 만족도에 대한 연구는 다양하게 이루어 졌지만 배드민 턴 동호인의 주로 발생되는 발목관절의 상해 이후 균형능력과 하지 근활성도에 대한 연구는 부족한 실정이다. 따라서 본 연구의 목적은 발목관절 불안정성을 가진 배드민턴 동호인들 대상으로 신경근 훈련 을 적용 후 균형능력과 하지 근활성도를 측정하여 발목관절 불안정 성을 가진 배드민턴 동호인에게 어떠한 영향을 미치는지 대해 알아 보고, 발목관절 불안정성의 개선과 부상예방 및 부상 이후 효과적인 관리를 위한 기초자료를 제공하고자 한다.

\section{연구 방법}

\section{1. 연구대상}

본 연구는 전남 $\mathrm{M}$ 시에 거주하는 배드민턴 동호인을 대상으로 자발 적 참여에 동의한 자를 선정하여 본 연구의 참여기준에 적합한 자로 각각 실험군 10 명, 대조군 10 명으로 나누어 연구를 진행 하였다. 대상 자의 선정기준은 1) 기능적 발목 불안정성 설문지의 항목 중 5 개 이상 을 만족하는 동호인, 2) 발목의 수술 경력이 없는 동호인, 3) 발목 관절 움직임이 정상의 생리적 범위를 초과하지 않는 동호인, 4) 완전한 체 중지지가 가능한 동호인, 5) 시각 및 청각에 의학적 문제가 없는 동호 인으로 본인 또는 보호자에게 본 연구에 대해 충분히 설명한 후 진행 하였다. 연구에 참여한 대상자의 일반적 특징은 Table 1과 같다.

\section{2. 실험방법}

본 연구가 진행되는 체육관은 전남 $\mathrm{M}$ 시 $\mathrm{S}$ 동에 위치한 실내체육 시설 에서 실시하였다. 실험군은 4 주간, 3 회/1주, 30 분/1일 동안 총 12 회 진

Table 1. General characteristics of the subjects

\begin{tabular}{lccc}
\hline Characteristic & Experimental group & Control group & $\mathrm{p}^{\prime}$ \\
\hline Number (person) & 10 & 10 & \\
Age (year) & $42.80 \pm 7.48$ & $45.10 \pm 8.43$ & 0.727 \\
Sex (male/female) & $6 / 4$ & $7 / 3$ & 0.513 \\
Dominant hand (right/left) & $8 / 2$ & $9 / 1$ & 0.613 \\
\hline
\end{tabular}

$p^{\prime}=$ Independent t-test. 


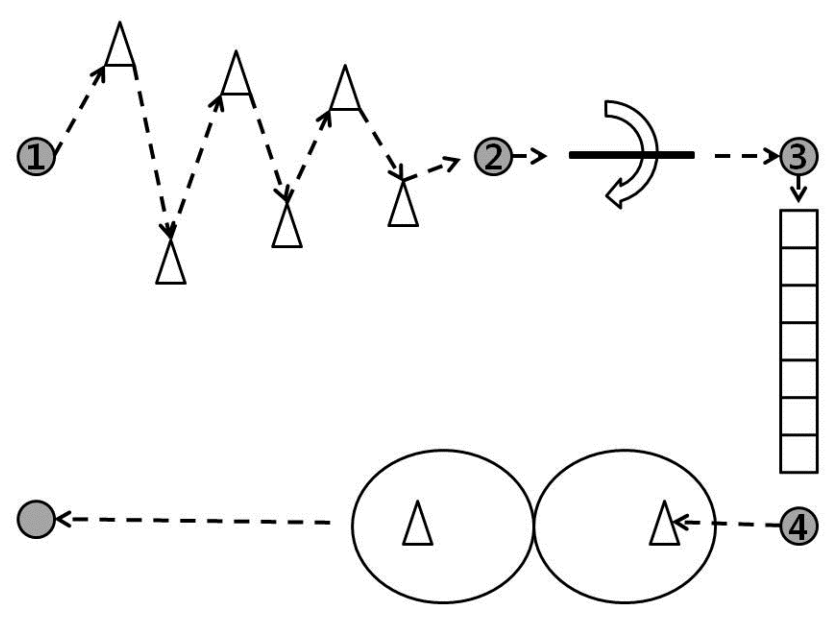

Figure 1. The method of neuromuscular training.

행 되며, 매회 준비운동 5 분과 정리운동 5 분, 본운동 20 분으로 진행 하였다. Myer 등 ${ }^{20}$ 의 방법을 변형하여 (1) 민첩성 훈련, (2) 옆으로 한발 뛰기, (3) 수직점프, (4) 8 자 한발뛰기 훈련을 1 회로 하여 실시 하였으며 점차 경기상황과 유사하게 난이도를 높였다(Figure 1). 대조군은 4주 간, 3 회/1주, 30 분/1일 동안 총 12 회 진행 되며, 매회 준비운동 5 분과 정 리운동 5 분, 본운동 20 분으로 진행하였다. 첫 주에서 둘째 주까지는 안정된 지지면에서 눈을 뜬 상태에서 손상측 발을 지지하고 건측 다 리를 엉덩관절과 무릎관절을 $90^{\circ}$ 로 들어올리고 양손은 편안한 자세 로 유지하며, 셋째 주부터 넷째 주까지는 에어로 스텝(Aero-step XL, TOGU, Germany) 위에서 실시하였다.

\section{1) 측정도구}

(1) 표면 근전도 시스템

하지의 근활성도를 측정하기 위하여 표면 근전도 시스템(MP100 EMG, Biopac System Inc., USA)을 이용하였고 여기에서 전환된 디지 털 신호는 개인용 컴퓨터에서 Acqknowledge 3.91 소프트웨어를 이용 하여 자료 처리하였다. ${ }^{21}$ 표면 근전도의 신호에 대한 피부 저항을 감 소시키기 위하여 부착부위의 털을 제거한 후, 소독용 알코올로 피부 를 깨끗이 하였다. 근전도 자료는 만성 발목 불안정성을 보이는 하지 의 앞정강근(tbialis Anterior), 긴종아리근(peroneus Longus), 장딴지근 (gastrocnemius)에서 수집하였고 표본 추출률(sampling rate)은 1,024 $\mathrm{Hz}$ 로 설정하였고, 잡음을 최소화하기 위하여 대역 여과 필터(notch filter) $60 \mathrm{~Hz}$, 대역통과필터(band pass filter) $30-500 \mathrm{~Hz}$ 를 사용 하였고, 수집된 신호는 실효치(RMS)로 변환하였다. ${ }^{22}$ 근전도의 수집된 테이 터를 일반화하기 위한 과정으로 앞정강근, 긴종아리근과 장딴지근의 최대 등척성 수축(maximal voluntary isometric contraction, MVIC)을 기준으로 측정된 값을 표준화하였다. 최대 등척성 수축 측정은 시작'
이라는 구호와 함께 각각의 동작을 5 초 유지하여 3 회 반복 측정하고, 각 동작의 수행 사이 1 분간 휴식을 취하고, 5 초 동안의 측정값을 RMS처리한 후 처음과 마지막 1 초를 제외 한 중간 3 초 동안의 평균 근 전도 신호량을 $100 \% \mathrm{MVIC}$ 로 사용한다. 또한 만성 발목 불안정성을 보이는 하지 측정 후 3 분간의 휴식 후 반대쪽 하지를 동일한 방법으 로 측정하였다. ${ }^{23,24}$

(2) 균형 능력 측정 시스템

균형 능력을 분석하기 위하여 Biorescue (RM Ingenierie, Rodez, France) 를 사용하였다. 이장비는 이동이 가능하며, 압력중심의 이동을 측정 하기 위한 사각형 모양의 힘판(force plate)과 압력중심의 이동을 보여 주는 모니터로 구성되어 있다. 검사 방법에는 정적 균형을 측정하기 위해 두 발로 서기를 60 초간 전방을 향하는 동안 신체 중심(center of pressure)의 총 궤적길이를 측정하였다. 동적 균형의 안정성 한계(limited of stability)를 측정하기 위해 전방의 모니터에서 지시하는 8개의 방향으로 체중 이동 시 중심점에서의 거리를 측정하였다. 모든 평가 는 3 회를 측정하여 얻은 결과 값의 평균값을 이용하였다. ${ }^{12,25,26}$

\section{2) 분석방법}

결과분석은 Windows SPSS 20.0 프로그램을 이용하여 처리하였다. 연 구대상자의 정규성 검증을 위해 독립표본 t-검정(independent t-test)을 실시하였고, 운동방법에 따른 그룹 간 근활성도와 균형능력을 비교 하기 위해 공분산분석(analysis of covariance, ANCOVA)을 실시하였 다. 통계학적 유의수준은 0.05 로 하였다.

\section{결 과}

\section{1. 그룹 간 하지 근활성도 비교}

그룹 간 중재 전, 후 앞정강근의 근활성도 비교에서 실험군은 $24.47 \pm$ $5.26 \%$ 에서 $39.13 \pm 3.15 \%$ 으로, 대조군은 $26.12 \pm 4.75 \%$ 에서 $36.16 \pm 2.66 \%$ 로 대조군과 비교하여 통계학적으로 유의한 차이가 있었다 $(\mathrm{p}<0.05)$. 긴종아리근의 근활성도 비교에서 실험군은 $48.22 \pm 2.46 \%$ 에서 72.70 $\pm 6.51 \%$ 으로, 대조군은 $48.94 \pm 2.48 \%$ 에서 $69.65 \pm 2.95 \%$ 로 대조군과 비 교하여 통계학적으로 유의한 차이가 있었다( $\mathrm{p}<0.005)$. 장딴지근의 근활성도 비교에서 실험군은 $51.75 \pm 3.15 \%$ 에서 $70.38 \pm 4.74 \%$ 으로, 대 조군은 $52.40 \pm 4.25 \%$ 에서 $62.56 \pm 2.78 \%$ 으로 대조군과 비교하여 통계 학적으로 유의한 차이가 있었다 $(\mathrm{p}<0.05)$ (Table 2).

\section{2. 그룹 간 균형능력 비교}

그룹 간 중재 전, 후 총 궤적거리 비교에서 실험군은 $89.47 \pm 12.26 \mathrm{~mm}$ 에서 $79.38 \pm 20.15 \mathrm{~mm}$ 로, 대조군은 $90.83 \pm 21.75 \mathrm{~mm}$ 에서 $86.16 \pm 21.86$ 
Table 2. Comparison of muscle activity between groups (Unit: \%MVIC)

\begin{tabular}{|c|c|c|c|c|c|c|}
\hline \multirow{3}{*}{ Test } & \multicolumn{2}{|c|}{ pre-test } & \multicolumn{2}{|c|}{ post-test } & \multirow{3}{*}{$F$} & \multirow{3}{*}{$p^{\prime}$} \\
\hline & Experiment & Control & Experiment & Control & & \\
\hline & \multicolumn{2}{|c|}{ Mean $\pm S D$} & \multicolumn{2}{|c|}{ Mean $\pm S D$} & & \\
\hline TA & $24.47 \pm 5.26$ & $26.12 \pm 4.75$ & $39.13 \pm 3.15$ & $36.16 \pm 2.66$ & 7.325 & $0.006^{*}$ \\
\hline PL & $48.22 \pm 2.46$ & $48.94 \pm 2.48$ & $72.70 \pm 6.51$ & $69.65 \pm 2.95$ & 9.564 & $0.001^{+}$ \\
\hline GC & $51.75 \pm 3.15$ & $52.40 \pm 4.25$ & $70.38 \pm 4.74$ & $62.56 \pm 2.78$ & 5.745 & $0.045^{*}$ \\
\hline
\end{tabular}

$p^{\prime}=$ ANCOVA.

TA: Tibialis anterior, PL: Peroneus longus, GC: Gastrocnemius. ${ }^{*} \mathrm{p}<0.05,{ }^{+} \mathrm{p}<0.005$.

Table 3. Comparison of balance between groups

\begin{tabular}{|c|c|c|c|c|c|c|}
\hline \multirow{3}{*}{ Test } & \multicolumn{2}{|c|}{ pre-test } & \multicolumn{2}{|c|}{ post-test } & \multirow{3}{*}{$\mathrm{F}$} & \multirow{3}{*}{$p^{\prime}$} \\
\hline & Experiment & Control & Experiment & Control & & \\
\hline & \multicolumn{2}{|c|}{ Mean $\pm S D$} & \multicolumn{2}{|c|}{ Mean $\pm S D$} & & \\
\hline WPL (mm) & $89.47 \pm 12.26$ & $90.83 \pm 21.75$ & $79.38 \pm 20.15$ & $86.16 \pm 21.86$ & 40.25 & $0.004^{*}$ \\
\hline $\operatorname{LOS}\left(\mathrm{cm}^{2}\right)$ & $137.75 \pm 13.45$ & $138.40 \pm 14.29$ & $160.38 \pm 14.74$ & $148.56 \pm 5.78$ & 12.45 & $0.016^{+}$ \\
\hline
\end{tabular}

$p^{\prime}=$ ANCOVA

WPL: Whole path length, LOS: Limited of stability.

${ }^{*} p<0.005,{ }^{+} p<0.05$.

$\mathrm{mm}$ 로 대조군과 비교하여 통계학적으로 유의한 차이가 있었다 ( $\mathrm{p}<0.05)$. 안정성 한계 비교에서 실험군의 $137.75 \pm 13.45 \mathrm{~cm}^{2}$ 에서 $160.38 \pm 14.74 \mathrm{~cm}^{2}$ 로, 대조군은 $138.40 \pm 14.29 \mathrm{~cm}^{2}$ 에서 $148.56 \pm 5.78 \mathrm{~cm}^{2}$ 로 대조군과 비교하여 통계학적으로 유의한 차이가 있었다 $(\mathrm{p}<0.05)$ (Table 3).

\section{고 찰}

과학 기술의 발달과 산업화의 진전에 따른 노동구조의 변화로 증가 된 여가 시간을 스포츠 활동에 할애하고 있다. ${ }^{27,28}$ 다양한 여가활동 중 배드민턴은 남녀노소를 막론하고 누구나 쉽게 접근할 수 있는 실 내스포츠로 단식과 복식, 혼합복식 등 다양한 방법으로 진행 할 수 있다. 배드민턴은 셔틀콕의 방향을 따라 경기장내를 뛰어 다니는 기 술과 체력을 필요로 한다. 또한 셔틀콕의 급격한 감속이나 빠른 가속 을 위해 신체를 전, 후, 좌, 우로 민첩하게 움직여야 하는 근력, 민첩성, 근 지구력, 균형능력, 순발력이 필요한 경기이다.29 이러한 급격한 방 향전환과 준비운동의 부족으로 인해 스포츠 활동 시 하지에 주로 발 생되는 운동상해의 종류 중 하나로 발목관절 염좌가 발생되게 된 다. ${ }^{30}$

기능적 발목 불안정성이란 발목관절 염좌로 인해 발생하는 구조 적인 손상을 말하며 근-건 조직뿐만 아니라 발목 주변의 기계적수용 기를 포함한 신경조직에 손상을 입게 되어 균형능력과 관절의 위치 감각의 저하로 인한 근육신경계(neuromuscular system) 결손을 말한 다. 기능적 발목 불안정성은 인대의 느슨함을 느끼는 기계적인 불안
정성뿐만 아니라 서있거나 움직일 때 반복적으로 휘청거림(giving away)을 경험하거나 반복적으로 발목관절 염좌를 경험하는 상태를 말하며, ${ }^{31}$ 이와 같은 반복적인 발목관절의 염좌는 만성 발목 불안정 성으로 이어진다.

$\mathrm{Lee}^{10}{ }^{10}$ 는 만성발목 불안정성을 가진 축구선수를 대상으로 8 주 동안 주 3 회 신경근 훈련을 실시한 그룹에서 균형능력의 유의한 차이를 보 였으며, $\mathrm{Kim}^{32}$ 은 발목 염좌를 경험한 남자 농구선수를 대상으로 4 주 간 점진적 재활 운동프로그램을 실시한 그룹에서 균형능력에서 유 의한 차이를 보였다. $\mathrm{Kim}^{33}$ 은 기능적 발목 불안정성이 있는 20 대 대 학생 30 명을 대상으로 4 주 동안 주 3 회 20 분 동안 가상현실을 이용한 훈련 그룹에서 균형능력의 유의한 차이를 보였다. 본 연구에서도 만 성 발목 불안정성을 가진 배드민턴 동호인에게 신경근 훈련을 6 주 동 안 주 3 회 30 분 동안 중재한 그룹에서 균형능력의 유의한 증가를 보 여 선행연구와 동일한 결과를 보였다. 이는 신경근 훈련을 통하여 고 유수용성감각과 척수반사 활동과 같은 신경근 조절능력이 증진 되 어 균형능력에 현저하게 영향을 미친 것으로 사료된다. 또한 Jeong 등 ${ }^{34}$ 은 24 명의 노인들에게 감각운동훈련을 6 주 동안 중재 한 그룹과 근 력 강화운동을 중재한 그룹과의 균형능력 비교에서 감각운동훈련 그룹이 통계학적으로 유의한 증가를 보였으며, 이는 균형조절을 위 해서는 체성 감각의 입력이 필수적이라고 하였다. 이러한 고유수용 성 감각의 증진은 근육의 반응시간을 향상시키고 자세조절 능력의 증진을 가져온다고 하였다. ${ }^{35}$ 본 연구에서도 만성 발목 불안정성을 가 진 배드민턴 동호인에게 신경근 훈련을 6 주 동안 주 3 회 30 분 동안 중 재한 그룹에서 균형능력의 유의한 증가를 보여 선행연구와 동일한 
결과를 보였다. 고유수용성 감각의 강화는 발목 주위 근육의 강화 훈 련과 가동범위를 정상으로 하는 것과 함께 중요한 요소이며, 고유수 용성 감각의 정확한 정보가 제공될 때 피드백과 피드 포워드가 효과 적으로 이루어져 ${ }^{33}$ 자세 조절능력의 증진에 영향을 미친 것으로 생각 된다.

Forestier와 Toschi는 ${ }^{36}$ 불안정한 지지면에서 균형 훈련이 앞정강근 과 긴 종아리근의 근활성도의 유의한 증가를 보였고, Nam 등 ${ }^{37}$ 은 만 성발목 불안정성을 가진 성인 남성 28명을 대상으로 균형 훈련을 실 시한 그룹에서 앞정강근과 긴종아리근에서 근활성도의 유의한차이 를 보였다. Strøm 등 ${ }^{38}$ 은 바닥에서 훈련보다 BOSU와 와블보드 위에 서 훈련이 긴종아리근의 활성도가 높다고 하였으며, $\mathrm{Kim}$ 은 ${ }^{39}$ 뇌졸중 환자를 대상으로 반웅크리기 자세에서 전신진동운동을 실시한 그 룹에서 앞정강근에서 근활성도의 유의한 차이를 보였다. 본 연구에 서도 만성 발목 불안정성을 가진 배드민턴 동호인에게 신경근 훈련 을 6 주 동안 주 3 회 30 분 동안 중재한 그룹에서 앞정강근, 긴종아리근 과 장딴지근의 근활성도의 유의한 증가를 보여 선행연구와 동일한 결과를 보였다. 이처럼 하지의 근활성도의 증가는 균형능력과 높은 상관관계가 있다고 하였고, ${ }^{24}$ 발목 관절의 정적 안정성과 동적 안정성 을 유지하기 위해서는 발목 주변근육의 근력과 고유수용성 감각의 기능을 유지하여야 안정성이 유지되고 재손상을 예방 할 수 있다고 하였다. 배드민턴처럼 급격한 방향전환, 가속과 감속, 점프와 같은 동 작들이 반복적으로 일어나는 스포츠 활동에서 발목 주변근육의 강 화훈련과 고유수용성 감각 훈련, 안정성 훈련이 복합된 신경근 훈련 이 만성 발목 불안정성을 가진 배드민턴 동호인의 발목 불안정성을 개선 및 재손상 예방을 위해 효율적으로 사용될 수 있을 것으로 생 각된다.

본 연구는 만성 발목 불안정성을 가진 배드민턴 동호인을 대상으 로 신경근 훈련을 6주간 실시한 후 하지 근활성도와 균형능력에 미치 는 영향을 분석하여 신경근 훈련의 효과를 알아보았다. 앞정강근, 긴 종아리근과 장딴지근의 근활성도(\%MVIC)값과 균형능력 값의 분석 을 통하여 신경근 훈련이 하지 근활성도와 균형능력 향상에 효과적 임을 알 수 있었다.

본 연구의 제한점으로 지역적 제한과 적은 대상자로 인해 모든 발 목 불안정성을 가진 배드민턴 동호인에게 일반화하기 어려웠고, 연구 대상자의 일상생활 통제에 어려움이 있었다. 향후 본 연구를 바탕으 로 발목 불안정성을 가진 배드민턴 동호인에게 신경근 훈련의 중재가 점프력과 민첩성에 미치는 영향에 대한 연구도 필요할 것이다.

\section{REFERENCES}

1. Park YW. Influence of the levels of participation in the badminton activ- ity on leisure satisfaction. Seoul University. Dissertation of Master's Degree. 2010.

2. Kong BH. Effects of participation motivation and exercise flow on leisure satisfaction and leisure attitude in badminton participants. Chosun University. Dissertation of Master's Degree. 2009.

3. Kang MW. Actual condition survey and coping methods on sport injuries of badminton amateur and professional athletes. Wonkwang University. Dissertation of Master's Degree. 2014.

4. Kim SY. The analysis of exercise injury types about badminton clubs in sport for all. Sangji University. Dissertation of Master's Degree. 2007.

5. Hubbard TJ, Kramer LC, Denegar CR et al. Contributing factors to chronic ankle instability. Foot Ankle Int. 2007;28(3):343-54.

6. Hertel J. Sensorimotor deficits with ankle sprains and chronic ankle instability. Clin Sports Med. 2008;27(3):353-70.

7. Yoon SW. The effects of whole-body vibration exercise on static and dynamic postural control in patients with chronic ankle instability. Yonsei University. Dissertation of Master's Degree. 2015.

8. Eric A, Mark D, Terese L et al. Dynamic postural stability deficits in subjects with self-reported ankle instability. Med Sci Sports Exerc. 2007; 39(3):397-402.

9. Buchanan AS, Docherty CL, Schrader J. Functional performance testing in participants with functional ankle instability and in a healthy control group. J Athl Train. 2008; 43(4):342-6.

10. Lee MK. Effects of neuromuscular training on postural control and functional performance in functional ankle instability soccer player. Sehan University. Dissertation of Master's Degree. 2015.

11. Lanzetta D, Cattaneo D, Pellegatta D et al. Trunk control in unstable sitting posture during functional activities in healthy subjects and patients with multiple sclerosis. Arch Phys Med Rehabil. 2004;85(2):279-83.

12. Park SK, Park SH. The effects of water-based exercise on physiological cost index and balance in stroke patients. J Kor Phys Ther. 2014;26(6): 411-7.

13. Paillard T, Noe F, Riviere T et al. Postural performance and strategy in the unipedal stance of soccer players at different levels of competition. J Athl Train. 2006;41(2):172-6.

14. Lim HW. The effect of motor imagery on onset time of leg muscle and ankle injury score of patients with functional ankle instability. J Kor Phys Ther. 2012;24(1):7-14.

15. Herman K, Barton C, Malliaras P et al. The effectiveness of neuromuscular warm-up strategies, that require no additional equipment, for preventing lower limb injuries during sports participation: a systematic review. BMC med. 2012;10(75):1-12.

16. Riemann BL, Myers JB, Lephart SM Comparison of the ankle, knee, hip, and trunk corrective action shown during single-leg stance on firm, foam, and multiaxial surfaces. Arch Phys Med Rehabil. 2003;84(1):90-5.

17. Santos MJ, Conceição J, de Araújo FG et al. Changes in postural control after a ball-kicking balance exercise in individuals with chronic ankle instability. J Athl Train. 2016 [Epub ahead of print].

18. Jackson K, Simon JE, Docherty CL. Extended use of kinesiology tape and balance in participants with chronic ankle instability. J Athl Train. 2016;51(1):16-21.

19. Linens SW, Ross SE, Arnold BL. Wobble board rehabilitation for improving balance in ankles with chronic instability. Clin J Sport Med. 2016;26(1):76-82. 
20. Myer GD, Ford KR, McLean SG et al. The effects of plyometric versus dynamic stabilization and balance training on lower extremity biomechanics. Am J Sports Med. 2006;34(3):445-55.

21. Park SK, Yang DJ, Kang JI et al. Biomechanical analysis of sitting up from a lying posture in stroke patients. J Kor Phys Ther. 2013;25(2):103-9.

22. Park SK, Yang DJ, Kang JI et al. The effects of water-based exercise on muscle activity and gait ability in stroke patients. J Kor Phys Ther. 2015; 27(5):369-74.

23. Kim JH. The effects of whole body vibration exercise on jump performance and quadriceps muscle activation in soccer player. J Kor Phys Ther. 2015;27(3):129-34.

24. Park SK, Kim JH. Effects of EMG-biofeedback training on total knee replacement patients' lower extremity muscle activity and balance. J Kor Phys Ther. 2013;25(2):81-7.

25. Park SH. The effects of water-based exercise on physiological cost index and balance in stroke patients. Sehan University. Dissertation of Master's Degree. 2015.

26. Park SK, Park SH. The effects of water-based exercise on physiological cost index and balance in stroke patients. J Kor Phys Ther. 2014;26(6): 411-7.

27. Jeon SY. The influence of badminton club activities on leisure satisfaction. Kookmin University. Dissertation of Master's Degree. 2004.

28. Kim YK. The effects of badminton club members achievement on sport commitment and satisfaction. Gachon University. Dissertation of Master's Degree. 2013.

29. Sobhani S, Dekker R, Postema K et al. Epidemiology of ankle and foot overuse injuries in sports: a systematic review. Scand J Med Sci Sports. 2013;23(6):669-86.
30. Jain TK, Wauneka CN, Liu W. Four weeks of balance training does not affect ankle joint stiffness in subjects with unilateral chronic ankle instability. Int J Sports Exerc Med. 2016;2(1):36-42.

31. Tropp H. Commentary: Functional ankle instability revisited. J Athl Train. 2002;37(4):512-5.

32. Kim JB. Effects of lateral ankle ligament sprain treatment according to the methods of muscular strength and balanced rehabilitation programs. DanKook University. Dissertation of Master's Degree. 2005.

33. Kim KJ. Effects of virtual reality training program with functional ankle instability. Dongshin University. Dissertation of Master's Degree. 2015.

34. Jeong TG, Park JS, Choi JD et al. The effects of sensorimotor training on balance and muscle activation during gait in older adults. J Kor Phys Ther. 2011;23(4):29-36.

35. McKeon PO, Hertel J. Systematic review of postural control and lateral ankle instability, partII: Is balance training clinically effective. J Athl Train. 2008;43(3):305-15.

36. Forester N, Toschi P. The effect of an ankle destabilization device on muscular activity while walking. Int J sports Med. 2005;26(6):464-70

37. Nam SM, Kim WB, Yun CK. Effects of balance training by knee joint motions on muscle activity in adult men with functional ankle instability. J Phys Ther Sci. 2016;28(5):1629-32.

38. Strøm M, Thorborg K, Bandholm T et al. Ankle joint control during single legged balance using common balance traning devices implications for rehabilitation strategies. Int J Sports Phys Ther. 2016;11(3):38899.

39. Kim JH. The effects of whole body vibration exercise on balance and lower extremity muscle activity in stroke patients. J Kor Phys Ther. 2013; 25(5):266-72. 